\title{
Anaphylaxis in a Newborn Due to Ampicillin
}

\author{
(1) Nagehan Katipoğlu, (1) Abdullah Barış Akcan, (1) Münevver Kaynak Türkmen
}

Adnan Menderes University Faculty of Medicine, Department of Pediatrics, Division of Neonatology, Aydın, Turkey

\begin{abstract}
Anaphylaxis, an allergic reaction that is rapid in onset, is rare in the neonatal period due to immaturity of the immunological system. A case of threeday-old male neonate with ampicillin-induced anaphylaxis is reported here. Although drug allergies are rare in newborns, due to their life-threaten features, close monitoring is important.

Keywords: Adverse effect, ampicillin, anaphylaxis, newborn
\end{abstract}

\section{Introduction}

Anaphylaxis is a serious allergic reaction that is rapid in onset and life threatening. After contact with an allergen, mast cells and basophiles release chemical mediators. Increased immunoglobulin $\mathrm{E}$ (IgE) is responsible for pathogenesis. The most common causes of anaphylaxis in children are food and medicines. Anaphylaxis caused by drugs are mostly seen in hospitals. Hypersensitivity reactions are common in childhood but they are rare in the neonatal period due to the immaturity of the immunological system (1).

We present this case, due to the ampicillin, which is a commonly used antibiotic in newborn intensive care units, and because of the rare occurrence of anaphylaxis in the newborn period. We would like to emphasize the importance of monitoring patients who are followed up in newborn intensive care units, have an immature immunologic system with respect to life-threatening drug allergies in order to take precautions and determine the treatment approach more effectively.

\section{Case Report}

A male infant was born by caesarean section at 36 weeks gestation with a birth weight of $3.235 \mathrm{~g}$. The mother was 36 years old. At birth, the male infant was tachypneic and had retractions, with an Apgar score of five at $1^{\text {st, }}$ and seven at $5^{\text {th }}$ minute after birth. He was hospitalized with a diagnosis of respiratory distress syndrome, intubated and surfactant was given. Since congenital pneumonia could not be distinguished, treatment with ampicillin ( $50 \mathrm{mg} / \mathrm{kg} / \mathrm{per}$ dose with 12-hour intervals) and amikasin (15 mg/kg/per dose with 24-hour intervals) was initiated. In his laboratory tests, the following data were obtained: hemoglobin: $17.7 \mathrm{~g} / \mathrm{dL}$, leukocyte: $18.130 \mu \mathrm{L}$ (neutrophil: $7200 / \mu \mathrm{L}$, lymphocyte: 8030/ $\mu \mathrm{L}$, eosinophil: $1240 / \mu \mathrm{L}$, monocyte: $1440 / \mu \mathrm{L}$, basophil: $220 /$ $\mu \mathrm{L})$, C-reactive protein (CRP): $0.13 \mathrm{mg} / \mathrm{L}$. Echocardiography revealed a patent foramen ovale. Extubated at the $24^{\text {th }}$ hour of his life and continued under observation in room air. There were no pathological indicators in his prenatal history. Paracetamol allergy was present in his father. On the third day of follow-up, ten minutes after the $50 \mathrm{mg} /$ 
kg ampicillin within 15 minutes by intravenous slow push without the extravasation (Penbisin ${ }^{\circledR} 500 \mathrm{mg}$ vial, i.E.Ulagay, İstanbul, Turkey) whole body hyperemia, cyanosis of the extremities, edema of the eyelids-back of the hands and feet, subcostal retraction and stridor evolved (Figure 1). His vital signs were as follows, heart rate: $180 /$ per minute, $\mathrm{SpO}_{2}$ $98 \%$, respiration rate: $70 /$ per minute, blood pressure: $80 / 60$ (65) $\mathrm{mmHg}$, body temperature: $36{ }^{\circ} \mathrm{C}$. The sudden onset fulminant clinical condition was observed as a drug allergy and $2 \mathrm{mg} / \mathrm{kg}$ intravenous pheniramine maleate was used due to accessibility as the $\mathrm{H} 1$ antagonist at that time. In blood gas parameters, mild metabolic acidosis was detected $(\mathrm{pH}$ : 7.26, $\mathrm{pCO}_{2}: 41 \mathrm{mmHg}, \mathrm{pO}_{2}: 50 \mathrm{mmHg}, \mathrm{HCO}_{3}: 18 \mathrm{mEq} / \mathrm{L}, \mathrm{BE}$ : -8 , lactate: $3.4 \mathrm{mmol} / \mathrm{L})$. During the $5^{\text {th }}$ minute of intravenous antihistamine treatment, respiratory distress and skin findings disappeared. Control whole blood count; hemoglobin: $18.3 \mathrm{~g} /$

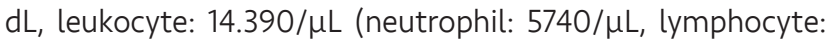

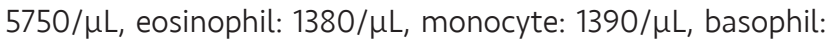
130/ $\mu \mathrm{L})$, CRP: $4.6 \mathrm{mg} / \mathrm{L}$ were detected. Complete urinalysis, a liver and kidney function test results were observed within the normal limits. There was no evidence of blood culture. Ampicillin therapy was discontinued and the follow-up was continued. Ampicillin specific IgE: $<0.1 \mathrm{kU} / \mathrm{L}$ (normal value: $<0.35 \mathrm{kU} / \mathrm{L}$ ), serum tryptase value was detected at $7.1 \mathrm{ug} / \mathrm{L}$ (normal value $<11.4 \mathrm{ug} / \mathrm{L}$ ). The patient, who had no biphasic reaction, was discharged on the $7^{\text {th }}$ day of life. The verbal consent was taken from the patient's parents.

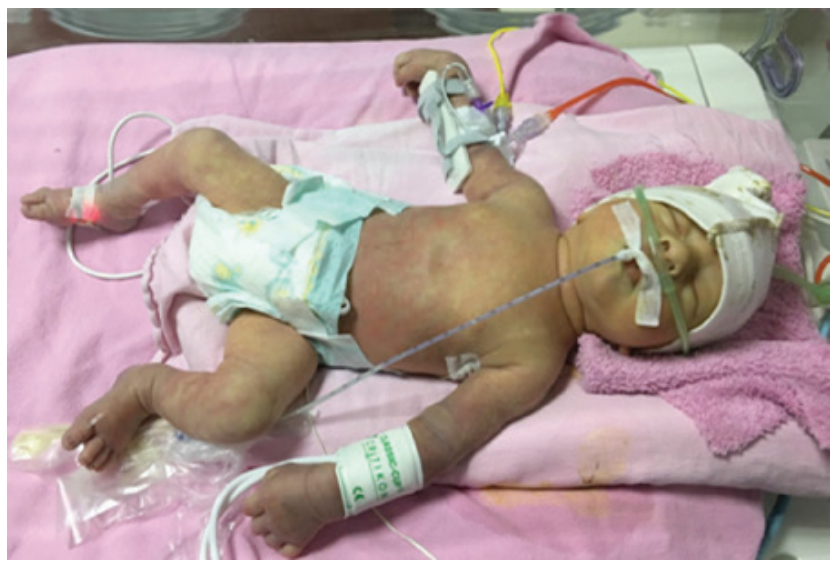

Figure 1. Hyperemia and cyanosis of the extremities with edema of the eyelids-back of the hands developed after ampicillin administration

\section{Discussion}

Anaphylaxis is a skin, respiratory, cardiovascular, gastrointestinal symptoms and signs of a hypersensitivity reaction and this reaction can be fatal. The immune system becomes susceptible to an allergen previously encountered. In the event of a recurrence, the clinical signs are revealed by the release of inflammatory mediators by mast cells (1).
The diagnosis of anaphylaxis is made by the appearance of signs and symptoms after the allergen encounter incident. Clinical findings such as flashing, generalized edema, dyspnea, bronchospasm, or hypotension are seen during the following minutes or hours. Mediators released from mast cells and basophils cause clinical signs with vasodilatation, increased capillary permeability and platelet aggregation (2). Diagnosis is based on clinical symptoms and findings rather than laboratory findings (1). Mast cells and basophiles may also be activated by IgE-independent mechanisms and may cause "anaphylactoid" reactions with similar clinical features. Anaphylaxis with IgE-mediated immunity or nonimmunization mechanisms is less common due to the immaturity of the immunological system during the neonatal period (3). For this reason, the diagnosis of anaphylaxis in the newborn is controversial and it is necessary to evaluate the differential diagnosis in detail. Neonatal sepsis and septic shock, which have clinical findings such as tachycardia, tachypnea and circulatory disturbances, as in our patient, are the first diagnosis that should be considered. Foreign body aspiration, respiratory and gastrointestinal malformations and sudden infant death syndrome should be considered in the differential diagnosis. In our patient, the acute phase reactants were negative (the cut off value of CRP is $5 \mathrm{mg}$ / $\mathrm{dL}$ ), immature/total neutrophil ratio in peripheral smear $<0.2$, good general condition and also clinical manifestations began after drug injection so we excluded a sepsis diagnosis. Hereditary angioedema has similar clinical findings to anaphylaxis but no response to adrenaline, antihistamines or steroids and there is also a family history (4). In our patient, there is no history to suggest hereditary angioedema in his family except a paracetamol allergy in his father. Also, the clinical manifestations began after ampicillin therapy, and there was a response to antihistamines. Therefore, a hereditary angioedema diagnosis was excluded.

The number of cases of anaphylaxis during the newborn period in the literature is few. After an intake of cefotaxime, ceftriaxone, ceftazidime, amikacin, cow milk proteins or hepatitis $B$ immunoglobulin, anaphylaxia cases have been reported $(1,4-8)$.

Ampicillin is an aminopenicillin group beta-lactam antibiotic effective against gram positive, gram negative and anaerobic microorganisms which is also commonly used in early sepsis treatment. Anaphylaxis due to penicillin-derived antibiotics is estimated to range from $1 \%$ to $10 \%$ worldwide, with a life-threatening anaphylaxis rate of $0.02 \%$ to $0.05 \%$ for all age groups (9).

Anaphylaxis is a condition requiring emergency treatment; oxygen support, monitorization, intravenous fluid therapy, adrenaline, antihistamine and steroid treatment are to be applied (1). Adrenaline (1/1000) is administered intramuscularly at a dose of $0.01 \mathrm{mg} / \mathrm{kg}$. Antihistamine and steroid treatment can be added. It is also seen in the literature 
that symptoms are corrected with antihistamine and dexamethasone only in the anaphylactic shock treatment in the newborn (8). In our case, clinical response was seen in five minutes with antihistamine only. No additional medication was needed as the clinical findings of the patient improved.

Approximately $6 \%$ of cases with anaphylaxis can recur after 1.3-28.4 hours of recovery (biphasic or recurrent anaphylaxis). Especially with serious anaphylactic cases, recurrences occur more frequently. Also, it should be kept in mind that a delay in adrenaline administration may facilitate this situation (10). There was no biphasic reaction during the 72-hour follow-up in our case.

Also, clinicians should always be reminded of the need to be cautious due to the possible mortal effects of intravenous ampicillin therapy commonly used in routine clinical practice.

\section{Ethics}

Informed Consent: The verbal consent was taken from the patient's parents.

Peer-review: Externally peer-reviewed.

\section{Authorship Contributions}

Surgical and Medical Practices: N.K., A.B.A., M.K.T., Concept: N.K., A.B.A., M.K.T., Design: N.K., A.B.A., Data Collection or Processing: N.K., A.B.A., M.K.T., Analysis or Interpretation: M.K.T., Literature Search: N.K., Writing: N.K., A.B.A.

Conflict of Interest: No conflict of interest was declared by the authors.
Financial Disclosure: The authors declared that this study received no financial support.

\section{References}

1. Simons FE. Anaphylaxis: Recent advances in assessment and treatment. J Allergy Clin Immunol 2009;124:625-36.

2. Topal E, Bakirtas A, Yilmaz O, et al. Severe anaphylaxis in children: a single-center experience. Pediatr Neonatol 2014;55:320-2.

3. Rupa P, Hamilton K, Cirinna M, Wilkie BN. A neonatal swine model of allergy induced by the major food allergen chicken ovomucoid (Gal d 1). Int Arch Allergy Immunol 2008;146:11-8.

4. Kendigelen P; BaktirClinic Of Anesthesiology And Reanimation Afşin State Hospital Afşin Kahramanmaraş Tureky M, Sucu A, Kaya G. Anaphylaxis after administration of amikacin containing sodium metabisulfite in a premature newborn. Arch Argent Pediatr 2016;114:195-8.

5. BabuTA, Sharmila V. Cefotaxime-induced near-fatal anaphylaxis in a neonate: A case report and review of literature. Indian I Pharmacol 2011;43:611-2.

6. Baumgartner-Bonnevay C, Choquet-Kastylevsky G, Putet G, Bleyzac N, Vial T, Descotes ). Anaphylactic shock associated with ceftriaxone therapy in a newborn. Arch Pediatr 2002;9:1050-2.

7. Soyer OU, Ozen C, Tiras U, Dallar Y. Anaphylaxis in a neonate caused by ceftazidime. Allergy 2010;65:1486-7.

8. Bulbul A, Karadag A, Köklü E, Pamuk U, Sarici SU. Anaphylactic shock due to hepatitis B immunoglobulin in a newborn. J Matern Fetal Neonatal Med 2010;23:1257-9.

9. Cetinkaya S, Tengir T. Penicillin Allergy and Penicillin Allergy Test: Review. J Pediatr 2008;17:175-82.

10. Lee JM, Greenes DS. Biphasic anaphylactic reactions in pediatrics. Pediatrics 2000;106:762-6. 